\title{
Simulation of Tsunami Impact on Sea Surface Salinity along Banda Aceh Coastal Waters, Indonesia
}

\author{
Maged Marghany \\ Additional information is available at the end of the chapter \\ http://dx.doi.org/10.5772/58570
}

\section{Introduction}

Constantly later the catastrophe of the Indian Ocean tsunami of Boxing Day 2004, research in tsunami geoscience has augmented evidently [1]. Scientists have attempted to comprehend the mechanisms of the wide scale of the Indian Ocean tsunami of 2004. Nevertheless, with great efforts done by scientists since Boxing day 2004, the Japanese tsunami with great disaster occurred. However, on March 11, 2011, a magnitude of $M_{w} 9.0$ earthquake struck off the coast of Honshu, Japan, sparking a tsunami that not only devastated the island nation, but also caused destruction and fatalities in other parts of the world, including Pacific islands and the United State (U.S.) West Coast [4].

Initial reports were eerily similar to those on December 26, 2004, when a massive underwater earthquake off the coast of Indonesia's Sumatra Island rattled the Earth in its orbit. The 2004 quake, with a magnitude of $\mathrm{M}_{\mathrm{w}}$ 9.1, was the largest one since 1964. But as in Japan, the most powerful and destructive aftermath of this massive earthquake was the tsunami that it caused. The death toll reached higher than 220,000 [1-3][10].

\subsection{Definitions of tsunami}

It is well known that the tsunami is the natural phenomena consisting of a series of waves generated when the waves are rapidly displaced on a massive scale. Tsunami (pronounced soo-NAH-mee) is a Japanese word which is meaning harbor ('tsu") and wave ("nami"). Tsunamis are fairly common in Japan and many thousands of Japanese have been killed by them in recent centuries. In this context, the term was coined by fishermen who returned to port to find the area surrounding the harbor devastated, in spite they had not been aware of any wave on high seas [2]. 
Haugen et al., [8] stated that tsunamis are long waves set in motion by an impulsive perturbation of the sea, intermediate between tides and swell waves in the spectrum of gravity water waves. Subsequently, Zahibo et al., [5] defined tsunami waves as surface gravity waves that occur in the ocean as the result of large-scale short-term perturbations (underwater earthquakes, eruptions of underwater volcanoes, landslides, rock falls, pyroclastic avalanche from land volcanoes entered in water, asteroid impact, and underwater explosions.

\subsection{Comments on tsunami definition}

In earlier times, seismic ocean waves were called "tidal" waves, incorrectly implying that they had some direct connection to the tides. In fact, when the tsunami approach coastal zone they began to characterize by a violent onrushing tidal rather than the sort of cresting waves that are generated by wind stress upon the sea surface. However, to eliminate this confusing the Japanese word "tsunami is used to describe the giant wave (Figure 1) in which is referring to a seismic wave and meaning harbor wave to replace the misleading term tidal wave. This tsunami is a synonym for seismic sea wave. In this regard, a tsunami is a seismic sea wave containing tremendous amounts of energy as a result of its mode of formation i.e. the factor that causing a seismic wave. Therefore, tsunamis are temporary oscillations of sea level with periods longer than wind, waves and shorter than tides for the tsunami, and shorter than a few days of storm surge [8].

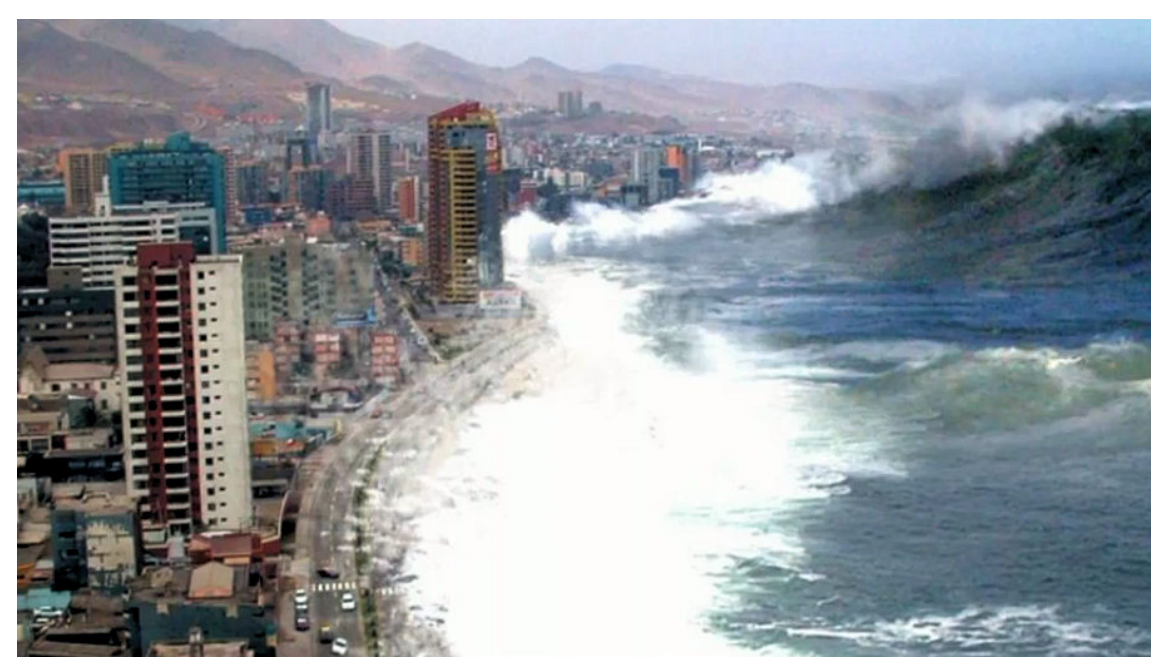

Figure 1. Giant Tsunami Wave [3].

\subsection{Tsunami characteristics}

The physical parameters of duration, length, propagation speed, and heights are the keys description of tsunami. In this regard, tsunamis have duration is ranged between 5 to 100 
minutes. They have long length which is ranged between100 m to1000 km. Further, tsunami propagation speed is between 1 to $200 \mathrm{~m} / \mathrm{s}$, and their heights can be up to tens of meters. Therefore, Zahibo et al., [5] stated that tsunami waves of the seismic origin are usually very long (50-1000 km). In this context, the source of the giant 2004 tsunami in the Indian Ocean (magnitude of $M_{w}$ 9.0-9.3) has approximated dimensions: (i) length; (ii) $670 \mathrm{~km}$; (iii) width 150 $\mathrm{km}$; and (iv) height $12 \mathrm{~m}$ [5].

This means that a tsunami can propagate long distances before it strikes a shoreline hundreds or thousands of kilometres from the earthquake source. To accurately model tsunami propagation over such large distances, the Earth's curvature should be taken into account. Other factors, such as Coriolis forces and dispersion, may also be important [7].

\subsection{Tsunami generation}

It is interesting to understand the mechanisms of tsunami generation. Generation mechanisms of tsunamis are geological events like land-and rockslides in fjords and lakes, submarine gravity mass flows and earthquakes. The Storage slide is one of the largest submarine slides in the world [8]. While the mechanism for generating the initial water waves by purely tectonic motions is reasonably well comprehended. Conversely, the modelling of tsunamis generated by submarine landslides is not yet explicated. Co-seismic deformation of the seafloor usually occurs rapidly relative to the propagation speeds of long water waves (Figure 2), allowing for simple specification of initial conditions by transferring the resultant permanent seafloor deformation to the free surface. However, sub-aerial and submarine landslides move less rapidly and the time-history of seafloor deformation (Figure 2) is important, necessitating the addition of source terms in the equations of motions. Compared with the understanding of earthquake-induced initial tsunami waves, the understanding of landslide-generated waves is marginal. Briefly, in terms of the semi-analytical empirical studies transferred the energy released by a moving block sliding from its initial position to its final position to solitary waves and calculated the height of the wave [9].

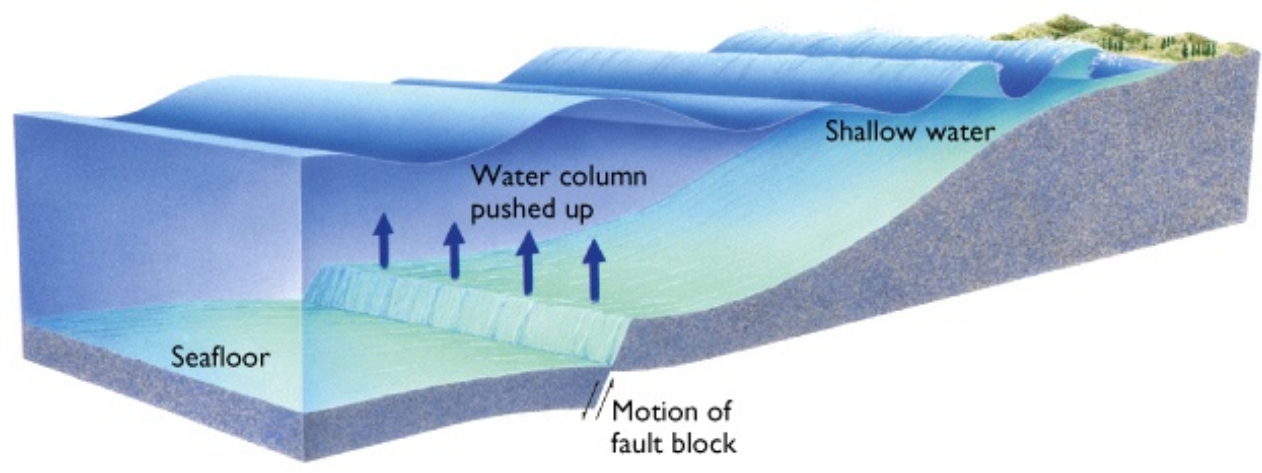

Figure 2. Tsunami generation due to motion of fault block. 


\subsection{Tsunami classifications}

Tsunami can be classified by the distance from their source to the area of impact; i.e., local and remote tsunami. Locally generated tsunami have short warning times and relatively short wave periods; remote tsunami have longer warning times and relatively long periods. Typical periods for tsunami range from 15 minutes for locally generated tsunami to several hours for remote tsunami. Typical run-up height for tsunami range up to $15 \mathrm{~m}$ at the coast, although most are much smaller. Storm surges on the other hand are caused by variations in barometric pressure and wind stress over the ocean. Decreasing barometric pressure causes an inverse barometer effect where sea level rises. This is usually a slow and large-scale effect and thus does not usually generate waves in the frequency range typical of tsunami. However, there can be short-period meteorological events (such as meteorological tsunami - rissaga) with time-scales of a few hours that may be important. Wind stress on the other hand has a wide range of time-scales and causes coastal sea-level setup as well as wind waves, where the setup depends on the wind direction, strength, and wave height. Storm surge periods range from several hours to several days. Typical heights for storm surge alone range up to $1.0 \mathrm{~m}$ for instance, along the coast of New Zealand, although most are usually less than $0.5 \mathrm{~m}$. Wind waves, on the other hand, can be quite large, producing wave setup and wave run-up of several meters in height.

In general, tsunamis can be categorized into: (i) microtsunami which has a small amplitude and would not even notice visually and (ii) local tsunami which has destructive impact due to its wide spread on coastal zone within hundred of kilometres and usually caused by plate tectonic movements. It might be internal wave named by internal tsunami due to its traveling along the a thermocline layer.

In a somewhat similar fashion, dropping a stone into a puddle of water creates a series of waves which radiate away from the impact point. In this context, the impact point of puddle of water is representing a sudden shifting of rocks or sediments on the ocean floor caused by cataclysmic event, such as a volcanic eruption, an earthquake, or a submarine landslide, can force the water level to drop $\geq 1 \mathrm{~m}$ generating a tsunami-a series of low waves with long periods, and long wavelengths (Figure 3). This indicates that the tsunami wavelength is bigger than its amplitude in the open ocean. Thus the tsunami height in the open ocean is approximately less than $1 \mathrm{~m}$ which it is not noticeable in open ocean. The tsunamis, however, cross the oceans at a rate of $\sim 750 \mathrm{~km} / \mathrm{hr}$ which is equivalent to a speed of a modern jet aircraft! Despite these phenomenal speeds, tsunami pose no danger to vessels in the open ocean. Indeed, the regular ocean swell would probably mask the presence of these low sea waves. The tsunamis, however, grow to height of $\geq 10 \mathrm{~m}$ as it impinges on a shoreline and flood the coast, sometimes with catastrophic results, including widespread property damage and loss of life.

\subsection{Geological descriptions of Sumatra earthquake}

In previous sections, the fundamental mechanism of tsunami was explained. Therefore, this section is devoted for tsunami of 26 December 2004 which is known as Sumatra-Andaman earthquake. Consequently, this disaster is called as Asian Tsunami in Asia region and also known as a Boxing day in the Australia, Canada, New Zealand, and the United Kingdom, 


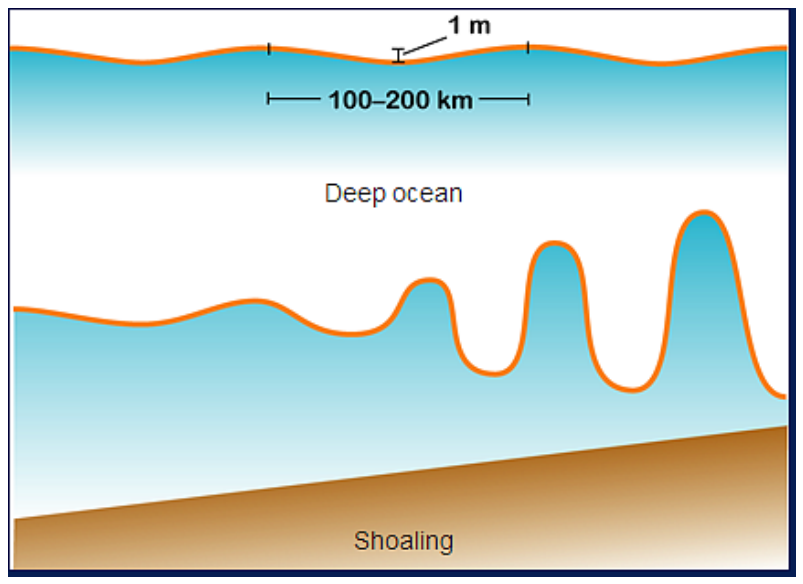

Figure 3. Tsunami Generation in Deep Water.

because it took place on Boxing Day. This earthquake was also reported to be the longest duration of faulting ever observed, lasting between 500 and 600 seconds (8.3 to 10 minutes), and it was large enough that it caused the entire planet to vibrate as much as half an inch, or over a centimeter.

\subsubsection{Epicenter of the giant tsunami}

The epicentre of the earthquake of the exceptionally high magnitude of 9.0 (Figure 4) is situated inside the trough as indicated between the northern edge of Sumatra and the small island of Simeulue, one member of the chain of islands next to the trench. Neither this trough relief reveals anything unusual nor does the comparatively moderate depth of the Sunda Trench of less than 5, $000 \mathrm{~m}$, the shallower sister of the conspicuous, adjacent Java-Trench southeast of it (Figure 5). The existing records of earthquakes of more than magnitude 5.5 in the Sumatra area since 1970 have clearly shown that their great majority, including the epicentre of the Giant Tsunami, occurred within the shallow strip between the coastline of Sumatra and the adjacent subduction trench rim; in other words: they occurred on the edge of the overriding plate!

According to Abbott [11], the Indian-Australian plate moves obliquely toward western Indonesia at 5.3 to $5.9 \mathrm{~cm} / \mathrm{yr}$ ( 2 to $2.3 \mathrm{in} / \mathrm{yr}$ ). The enormous, ongoing collision results in subduction-caused (Figure 6) earthquakes that are frequent and huge. Many of these earthquakes send off tsunami. On 26 December 2004, $1.200 \mathrm{~km}$ (740 mi) long fault rupture began as $100 \mathrm{~km}(62 \mathrm{mi})$ long portion of the plate tectonic boundary ruptured and slipped during a minute (Figure 6). The rupture then moved northward at $3 \mathrm{~km} / \mathrm{sec}(6,700 \mathrm{mph})$ for four minutes. Then slowed to $2.5 \mathrm{~km} / \mathrm{sec}(5,6000)$ during the next six minutes. At the northern end of the rupture, the fault movement slowed drastically and only traveled tens of meters during the next hour. It appears that a bend or scissors like tear in the subduction plate may have delayed the full rupture in December 2004. 


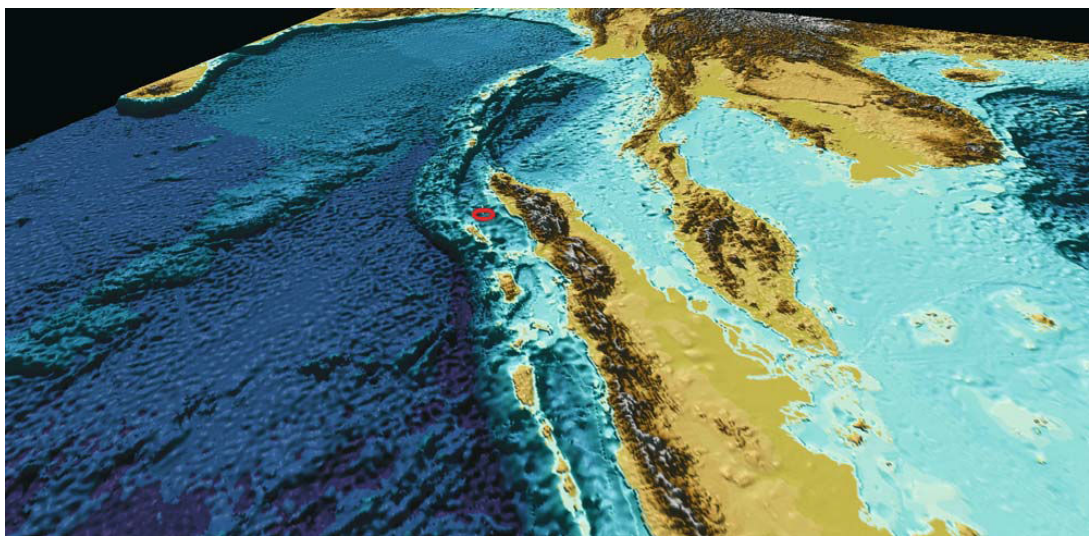

Figure 4. Epicenter of Giant Tsunami

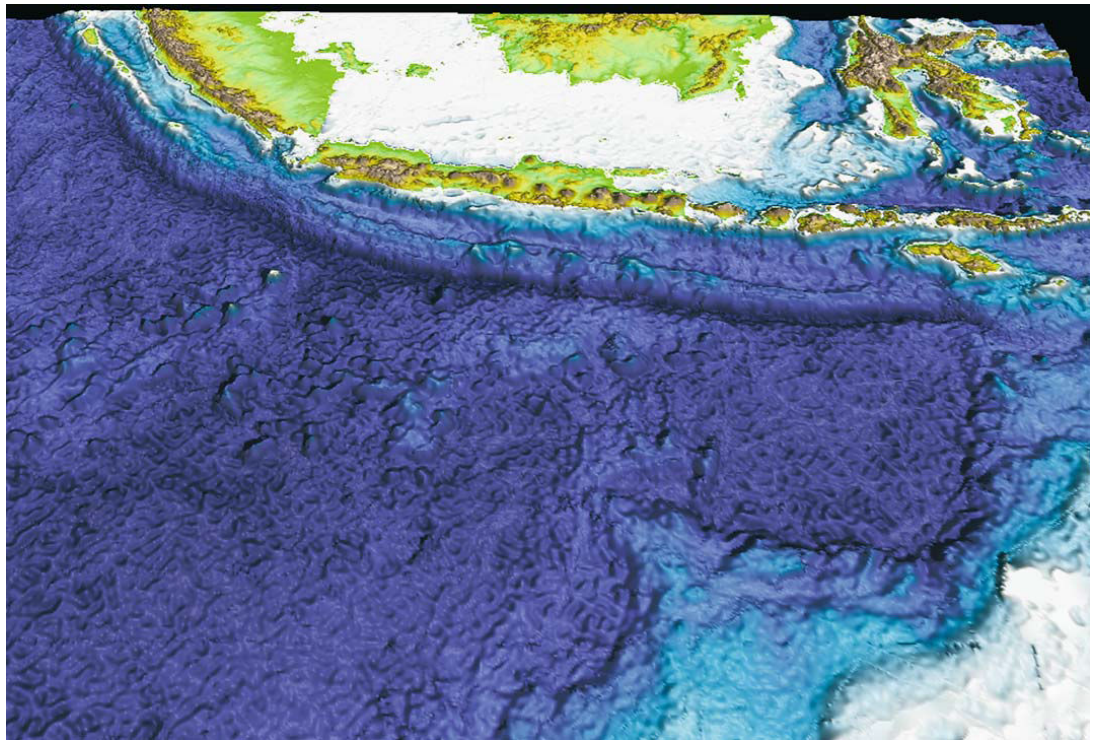

Figure 5. Java Trench.

Shulgin et al., [13] stated that the tectonics around Northern Sumatra are predominantly controlled by the subduction of the oceanic Indo-Australian plate underneath Eurasia. The current convergence rate offshore North-ern Sumatra is estimated at $51 \mathrm{~mm} / \mathrm{yr}$. The increasing obliquity of the convergence northwards from the Sunda Strait results in the formation and development of a number of arc-parallel strike-slip fault systems (Figure 7). The most significant are the Sumatra and the West Andaman Fault systems, accom-modating arc-parallel 

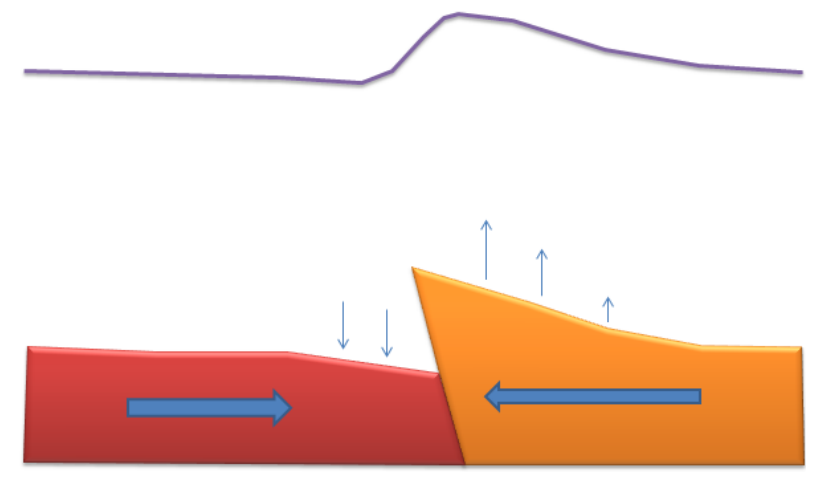

Figure 6. Deformation of sea Flooar and Sea Surface.

strain offshore central-southern Sumatra. For the Mentawai fault system. recent findings suggest deforma-tion dominated by backthrusting.

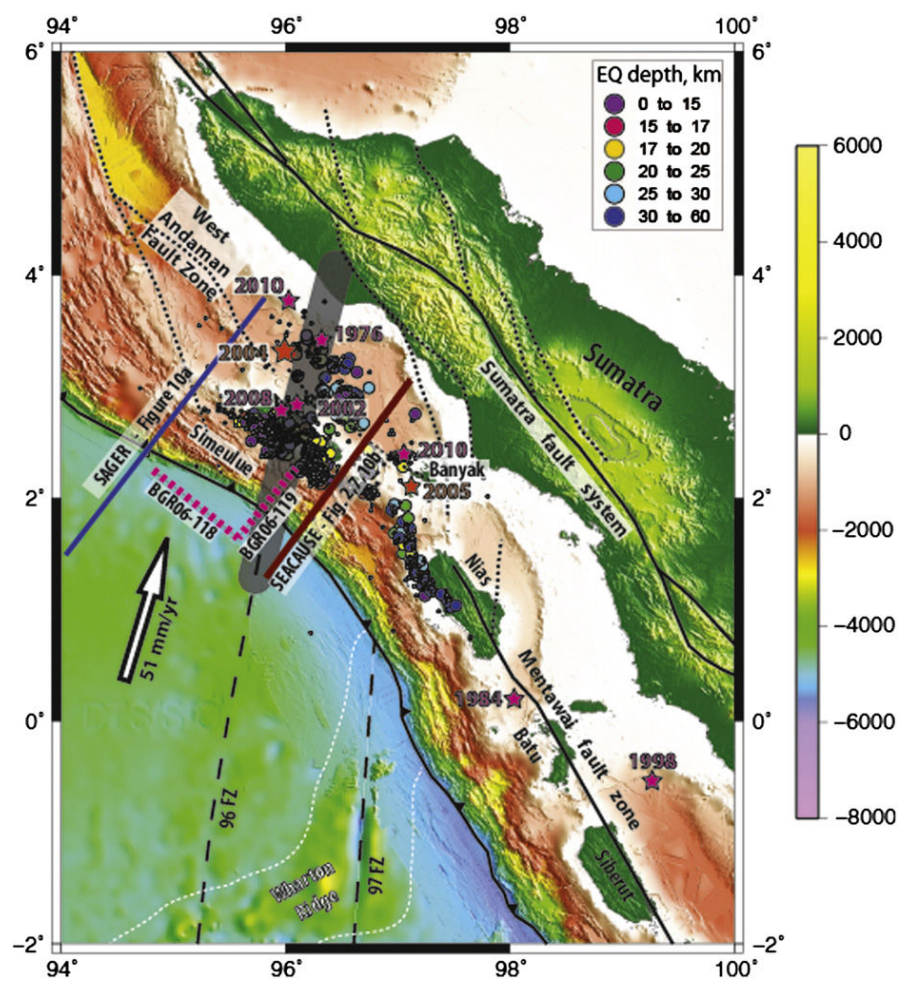

Figure 7. Subduction of Indian-Australian plate beneath Indonesia Shulgin et al., [13] 
Subsequently, Kelmelis et al., [10], the Indo-Australian plate is moving approximately 40 to 50 $\mathrm{mm}$ per year to the northeast, and the earthquake ruptured at the subduction zone boundary or interpolate thrust boundary (Figure 8). On the fault the earthquake had a maximum slip of approximately 15 to 20 meters with an average slip of $>5$ meters along the full length of the rupture. The sea floor overlying the thrust fault would have been raised by several meters. Further, velocities of displacement along 1200 to 1300 kilometres of the fault with at least three major energy bursts during the propagation of the rupture (50 to 150 seconds, 280 to 340 seconds, and 450 to 500 seconds.

\section{Sumatra-Andaman Earthquake $(M=9.2)$}

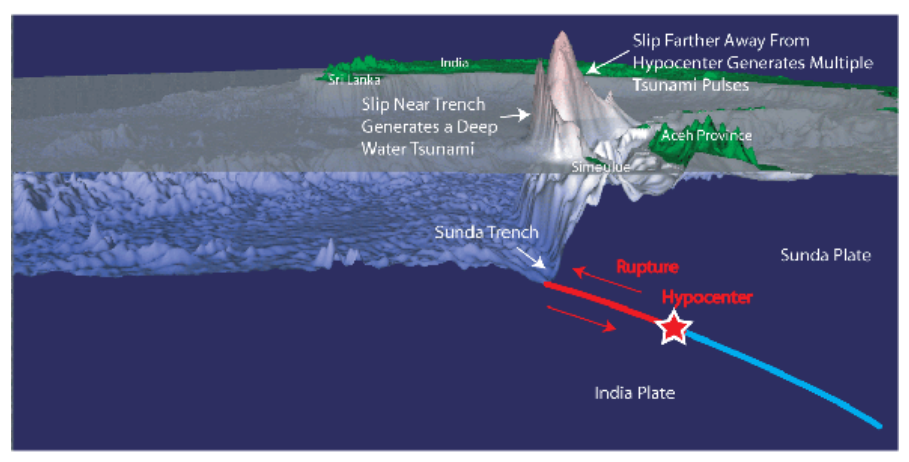

\section{Northern Sumatra Earthquake $(M=8.6)$}

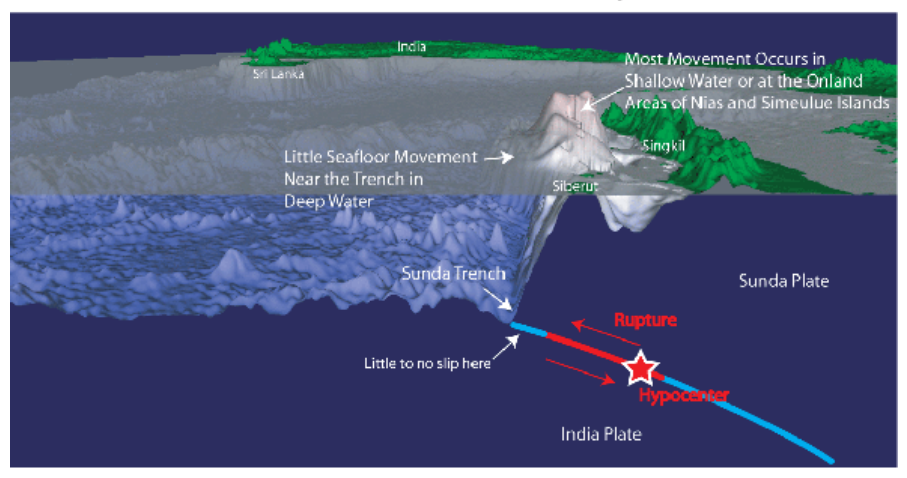

Figure 8. Location of Hypocenter of 2004.

\subsection{4 tsunami wave propagation}

At 00:58:53 UTC (07:58:53 local time) December 26, 2004, an undersea earthquake was occurred along a tectonic subduction zone in which the India Plate. In general Figure 9 shows that the 
tsunami reaches Phuket and Sri Lanka coasts in two hours after the earthquake, and African coast in 8-11 hours. The tsunami propagation is also animated (up to 5 hours) from a $1200 \mathrm{~km}$ fault. The red color means that the water surface is higher than normal, while the blue means lower. It indicates that initial tsunami to the east (e.g., Phuket) began with receding wave, while to the west (e.g., Sri Lanka) large wave suddenly reached. The darker the color, the larger the amplitude. The tsunamis were larger in the east and west directions.

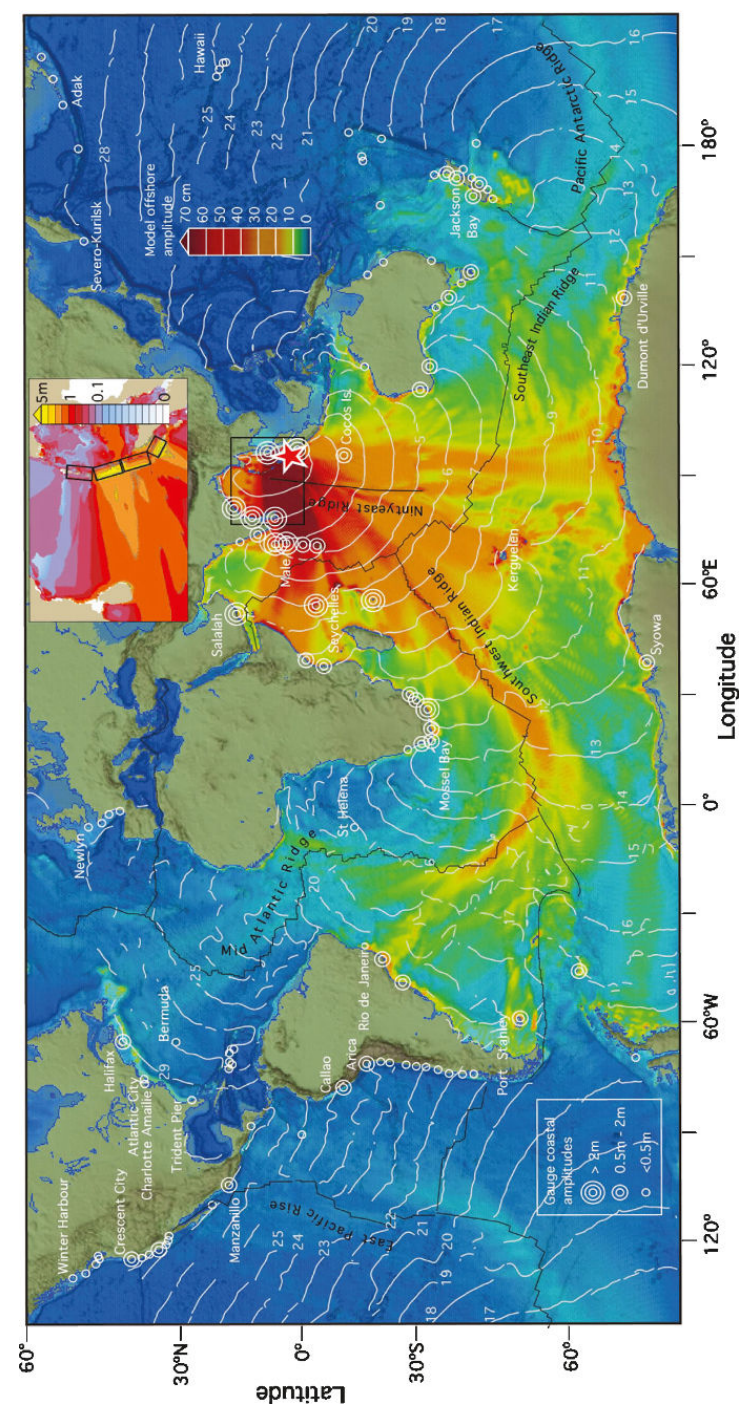

Figure 9. Tsunami wave propagation during 2004 [14]. 
The tsunami was caused by movement along a fault line running through the seabed of the Indian Ocean. As the fault runs north-south, the waves Travelled out across the ocean in mainly easterly and westerly direction with duration of 7 hours that shook the world. At 00.58 GMT, an undersea earthquake measuring 9.3 on the Richter Scale occurs off Indonesia. At +15 minutes later, the Indonesia Island of Sumatra, close to epicenter of the quake, is hit by the full force of tsunami. Many towns and villages in Aceh province on the western tip of the island are completely washed away, and the capital, Banda Aceh, is destroyed.

The remote Andaman which is lying only $100 \mathrm{~km}$ from the epicenter of the earthquake was struck within +30 minutes later. An hour after it hit Sumatra, the tsunami reached Thailand. It had lessened slightly in height and power but still struck the Thai coast with incredible force and the sea surged out for about $200 \mathrm{~m}$. One of the worst-hit places was Sri-Lanka, which lay almost directly west of the earthquake's epicenter. The tsunami wave reached Sri Lanka within +2.00 hours later. The tsunami height recorded in Sri Lanka ranged between 5 to $10 \mathrm{~m}$ (Table 1).

\begin{tabular}{ll}
\hline Location & Heights \\
\hline Sri Lanka, east coast & $5-10 \mathrm{~m}$ \\
\hline India, east coast & $5-6 \mathrm{~m}$ \\
\hline Andaman Islands & $>5 \mathrm{~m}$ \\
\hline Phuket, Thailand & $3-5 \mathrm{~m}$ \\
\hline Kenya & $2-3 \mathrm{~m}$ \\
\hline
\end{tabular}

Table 1. Measured Tsunami Wave Heights on Boxing Day

With no continental shelf to lift the tsunami's waves as they near shore, the Maldives gets off relatively lightly within +3.30 hours. Finally tsunami waves strike Africa coast within +7 hours. The wave height along Kenya coast was between 2 and $3 \mathrm{~m}$ (Table 1).

Further, the Christmas tsunami was so powerful it actually sped up the rotation of the Earth reducing the length of its sidereal day. The earthquake that spawned it also caused the Earth to vibrate all over by as much as $1 \mathrm{~cm}$. In this regard, the critical question may be raised is what the tsunami effects on the ocean physical properties such as temperature and salinity? In fact, there are no many studies have been conducted to answer this question. Temperature and salinity are the main parameters can be used to describe the ocean status. Both parameters can produce vertical current movement because of the their gradient changes. In addition, water density changes are function of gradual changes of temperature and salinity.

\subsection{Hypotheses and objective}

Concern with above prospective, we address the question of tsunami 's impact on Sea Surface Salinity (SSS) pattern changes pro and post tsunami event of 2004. This is demonstrated with Moderate-resolution Imaging Spectrometer (MODIS) i.e. the Aqua/MODIS data level IB reflectance satellite data using least square algorithm. Three hypotheses are examined: 
i. Least square algorithm can be used to retrieve Sea Surface Salinity in MODIS satellite data during and post tsunami disaster;

ii. Least square algorithm is automatic algorithm for retrieving SSS for short periods i.e. couple of days;

iii. There is changes in SSS pattern post tsunami 2004 event along Banda Aceh coastline.

\section{Study area}

The study area is located along the western coastal zone of Aceh with boundaries of latitudes $3^{\circ} 30^{\prime} \mathrm{N}$ to $6^{\circ} 30^{\prime} \mathrm{N}$ and longitudes of $93^{\circ} 30^{\prime} \mathrm{E}$ to $99^{\circ} 30^{\prime} \mathrm{E}$ (Figure 10). The Sunda trench is running north-south along the coastal waters of Aceh towards the Andaman Sea. Running in a rough north-south line on the seabed of the Andaman Sea is the boundary between two tectonic plates, the Burma plate and the Sunda Plate. These plates (or microplates) are believed to have formerly been part of the larger Eurasian Plate, but were formed when transform fault activity intensified as the Indian Plate began its substantive collision with the Eurasiancontinent. As a result, a back-arc basin center was created, which began to form the marginalbasin which would become the Andaman Sea, the current stages of which commenced approximately 3-4 million years ago (Figure 11). On December 26, 2004, a large portion of the boundary between the Burma Plate and the Indo-Australian Plate slipped, causing the 2004 Indian Ocean earthquake. This megathrust earthquake had a magnitude of 9.3. Between 1300 and 1600 kilometers of the boundary underwent thrust faulting and shifted by about 20 meters, with the sea floor being uplifted several meters. This rise in the sea floor generated a massive tsunami with an estimated height of 28 meters (30 ft) [14].

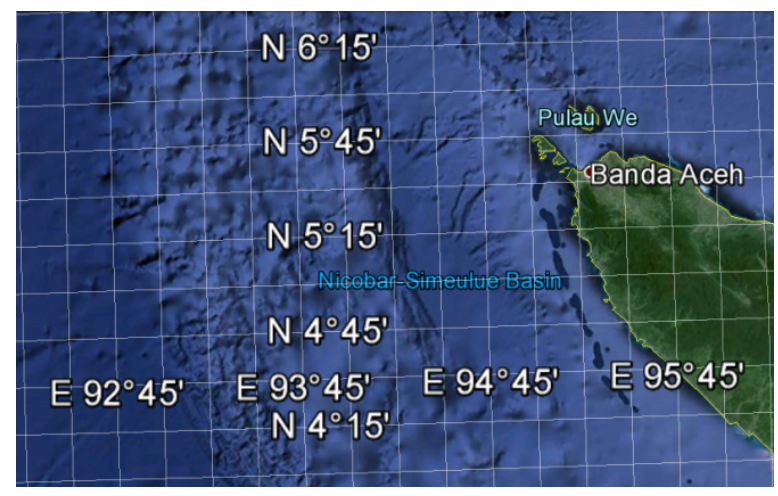

Figure 10. Location of study area. 


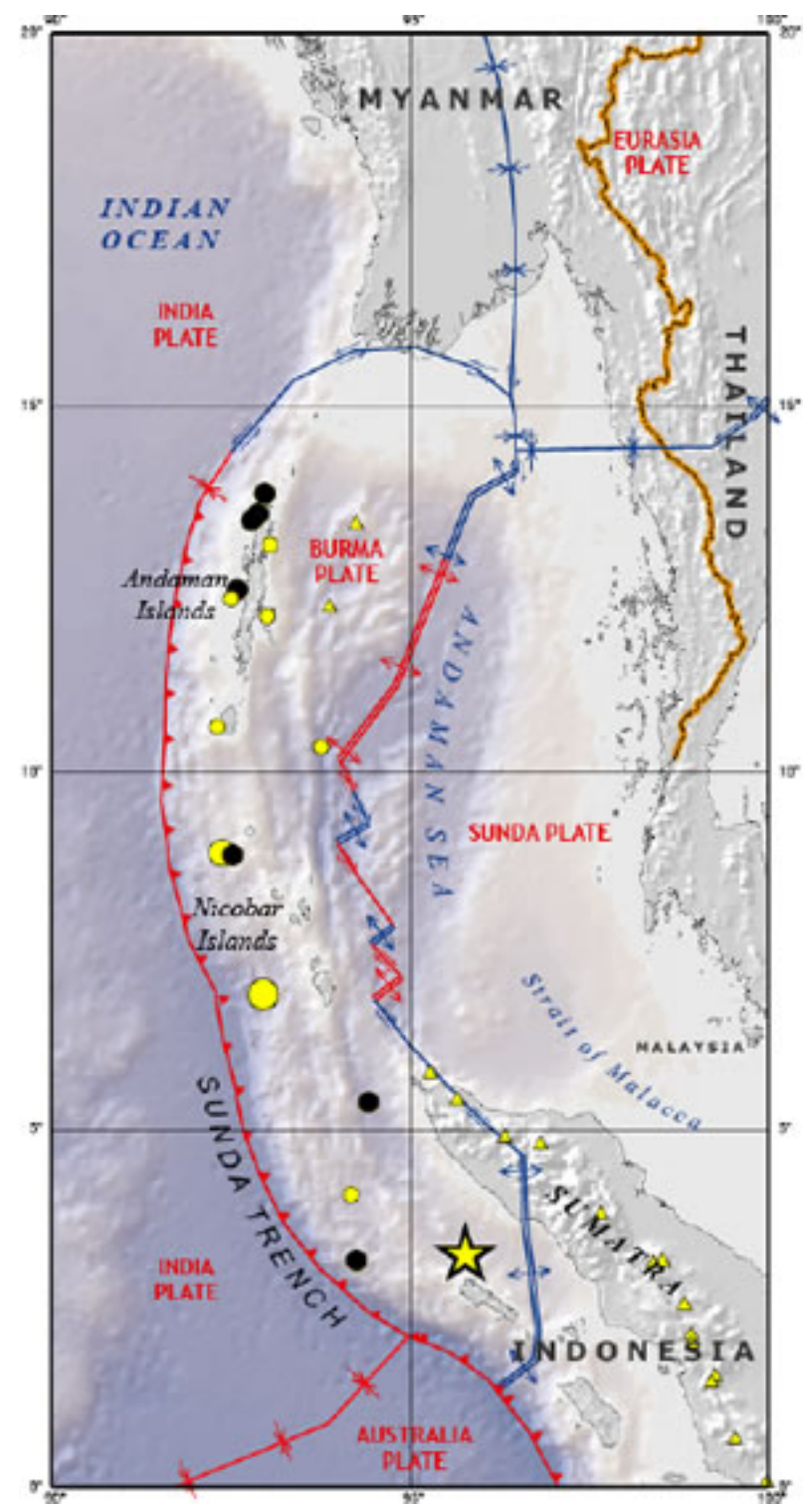

Figure 11. Location of Sunda Trench

The average depth of the sea is about 1,000 meters $(3,300 \mathrm{ft})$. The northern and eastern parts are shallower than 180 meters (600 ft) due to the silt deposited by the Irrawaddy River. This major river flows into the sea from the north through Burma. The western and central areas are $900-3,000$ meters deep (3,000-10,000 ft). Less than 5\% of the sea is deeper than 3,000 meters 
$(10,000 \mathrm{ft})$, and in a system of submarine valleys east of the Andaman-Nicobar Ridge, the depth exceeds 4,000 meters (13,200 ft). The sea floor is covered with pebbles, gravel and sand [14].

Further, the climate and water salinity of the Andaman Sea and Aceh are mostly determined by the monsoons of southeast Asia. Air temperature is stable over the year at $26^{\circ} \mathrm{C}$ in February and $27^{\circ} \mathrm{C}$ in August. Precipitation is as high as 3,000 mm/year and mostly occurs in summer. Sea currents are south-easterly and easterly in winter and south-westerly and westerly in summer. The average surface water temperature is $26-28^{\circ} \mathrm{C}$ in February and $29^{\circ} \mathrm{C}$ in May. The water temperature is constant at $4.8^{\circ} \mathrm{C}$ at the depths of $1,600 \mathrm{~m}$ and below. Salinity is 31.5$32.5 \%$ (parts per thousand) in summer and $30.0-33.0 \%$ in winter in the southern part. In the northern part, it decreases to $20-25 \%$ o due to the inflow of fresh water from the Irrawaddy River. Tides are semidiurnal (i.e. rising twice a day) with the amplitude of up to $7.2 \mathrm{~m}$ [23].

\section{Least square model}

In this section, we present the theoretical model of split window method that relates MODIS sea surface salinity with in situ salinity measured by thermal infrared sensors, these include multi-channel methods. We assume the MODIS image radiance $I$ within multi-channels $i$ have a linear relationship with measured sea surface salinity (SSS). A useful extension of linear function of $k$ channels as in

$$
S S S=b_{0}+b_{1} I_{1}+b_{2} I_{2}+b_{3} I_{3}+\ldots \ldots \ldots \ldots+b_{k} I_{k}+\varepsilon
$$

The model may be written in terms of the observations as

$$
S S S=b_{0}+\sum_{i=1}^{k} b_{i} I_{i}+\varepsilon
$$

where SSS is the measured sea surface salinity, $k$ is a number of MODIS radiance bands which equals 7 bands, $b_{0}, b_{i}$ are constant coefficient of linear relationship between MODIS radiance data $(I)$ and $\varepsilon$ is residual error of SSS estimated from selected MODIS bands. The unknown parameters in equation 2 , that are $b_{0}$ and $b_{i}$ may be estimated by a general least square iterative algorithm. This procedures requires certain assumptions about the model error component $\varepsilon$. Stated simply, we assume that the errors are uncorrelated and their variance is $\sigma_{\varepsilon}{ }^{2}$. In general, if $\varepsilon_{i}$ and $\varepsilon_{j}$ are two uncorrelated errors, then their covariance is zero, where we define the covariance as

$$
\operatorname{Cov}\left(\varepsilon_{i}, \varepsilon_{j}\right)=E\left(\varepsilon_{i} . \varepsilon_{j}\right)
$$


The least-square estimator of the $b_{i}$ minimizes the sum of squares of the errors, say

$$
S_{E}=\sum_{j=1}^{n}\left(S S S_{j}-b_{0}-\sum_{i=1}^{k} b_{i} I_{i}\right)^{2}=\sum_{j=1}^{n} \varepsilon_{j}^{2}
$$

where $S S S_{j}$ is the value of $S S S$ measured at $I_{i}, n$ is the total number of data points and $n \geq k$. It is necessary that the least squares estimators satisfy the equations given by the $k$ first partial derivatives $\frac{\partial S_{E}}{\partial b_{i}}=0, i=1,2,3, \ldots . ., k$ and $j=1,2,3, \ldots ., n$. Therefore, differentiating equation 4 with respect to $b_{i}$ and equating the result to zero we obtain

$$
\begin{aligned}
& \hat{n} b_{1}+\left(\sum_{j=1}^{n} I_{2 j}\right) \hat{b_{2}}+\left(\sum_{j=1}^{n} I_{3 j}\right) \hat{b_{3}}+\ldots+\left(\sum_{j=1}^{n} I_{k j}\right) \hat{b_{k}}=\sum_{j=1}^{n} S S S_{j} \\
& \left(\sum_{j=1}^{n} I_{2 j}\right) \hat{b_{1}}+\left(\sum_{j=1}^{n} I^{2}{ }_{2 j}\right) \hat{b_{2}}+\ldots+\left(\sum_{j=1}^{n} I_{2 j} I_{k j}\right) \hat{b_{k}}=\sum_{j=1}^{n} I_{2 j} S S S_{j} \\
& \left(\sum_{j=1}^{n} I_{k j}\right) \hat{b_{1}}+\left(\sum_{j=1}^{n} I_{k j} I_{2 j}\right) \hat{b_{2}}+\ldots+\left(\sum_{j=1}^{n} I_{k j j}^{2}\right) \hat{b_{k}}=\sum_{j=1}^{n} I_{k j} S S S_{j}
\end{aligned}
$$

The equations (5) are called the least-squares normal equations. The $\hat{b_{k}}$ found by solving the normal equations (5) are the least-squares estimators of the parameters $b_{i}$. The only convenient way to express the solution to the normal equations is in matrix notation. Note that the normal equations (5) are just a $k x k$ set of simultaneous linear equations in $k$ unknowns (the $\left\{b_{k}\right\}$ ). They may be written in matrix notation as

$$
H \hat{b}=h
$$

where

$$
\begin{aligned}
H & =\left[\begin{array}{cccc}
n & \sum I_{2 j} & \ldots . . & \sum I_{k j} \\
\sum I_{2 j} & \sum I_{2 j}^{2} & \ldots . . & \sum I_{2 j} I_{k j} \\
\sum I_{3 j} & \sum I_{3 j} I_{2 j} & \ldots . . & \sum I_{3 j} I_{k j} \\
\ldots \ldots \ldots & \ldots \ldots \ldots \ldots & \ldots \ldots & \ldots \ldots \ldots . \\
\hdashline I_{k j} & \sum I_{k j} I_{2 j} & \ldots \ldots . . & \sum I_{k j}^{2}
\end{array}\right] \\
\hat{b} & =\left[\begin{array}{c}
b_{1} \\
\hat{b_{2}} \\
\vdots \\
\vdots \\
\vdots \\
b_{k}
\end{array}\right] \text { and } h=\left[\begin{array}{l}
\sum S S S_{j} \\
\sum I_{2 j} S S S_{j} \\
\vdots \\
\sum I_{k j} S S S_{j}
\end{array}\right]
\end{aligned}
$$


Thus, $H$ is a $k x k$ estimated matrix of MODIS radiance bands that used to estimate sea surface salinity, $b$ and $h$ are both $k \times 1$ column vectors. The solution to the least-squares normal equation is

$$
\hat{b}=H^{-1} h
$$

where $H^{-1}$ denotes the inverse of the matrix $H$. Given a solution to least squares normal equations, the retrieval $S S S_{M O D I S}$ is estimated using the fitted multiple regression model of equation 2 as given

$$
S S S_{\text {MODIS }}=\hat{b_{1}}+\sum_{i=1}^{k} \hat{b}_{i} I_{i}
$$

Following Sonia et al., (2007), $\varepsilon$ errors that represents the difference between retrieved and in situ SSS are computed within $10 \mathrm{~km}$ grid point interval and then averaged over all grid points having the same range of distance to coast, where the bias $\varepsilon$ on the retrieved $S S S_{\text {MODIS }}$ is given by:

$$
\varepsilon=\frac{\sum_{i=1}^{N}\left(S S S_{M O D I S}-S S S_{\text {situ }}\right)}{N}
$$

where $S S S_{\text {MODIS }}$ is the retrieved sea surface salinity from MODIS satellite data, $S S S_{\text {situ }}$ is the reference sea surface salinity on grid point $i$ and $N$ is the number of grid points. Then, the empirical formula of $S S S_{\text {MODIS }}$ (psu) which is based on equations 8 and 9 is

$$
\operatorname{SSS}_{\text {MODIS }}(\mathrm{psu})=27.40+2.0 I_{1}-3.4 I_{2}+2.0 I_{3}+2.2 I_{4}+1.8 I_{5}+0.3 I_{6}+-1.8 I_{7} \pm 1.1
$$

This equation is different than the equation was obtained by Wong et al. [21] in terms of constant coefficient of linear model and involving the retrieved $S S S_{M O D I S}$ bias value. Finally, root mean square of bias (RMS) is used to determine the level of algorithm accuracy by comparing with in situ sea surface salinity. Further, linear regression model used to investigate the level of linearity of sea surface salinity estimation from MODIS data. The root mean square of bias equals [17]

$$
R M S=\left[N^{-1} \sum_{i=1}^{N}\left(S S S_{\text {MODIS }}-S S S_{\text {situ }}\right)^{2}\right]^{0.5}
$$




\section{Results and discussion}

The tsunami impact on sea surface salinity has been examined on three MODIS satellite data along Aceh coastal waters. These data are acquired on $23^{\text {rd }}, 26^{\text {th }}$ and $27^{\text {th }} 2004$ which represent pro, and post tsunami event, respectively (Figure 12). According to Marghany et al., [18], Moderate Resolution Imaging Spectroradiometer (MODIS) has $1 \mathrm{~km}$ spatial resolution and having 36 bands which are ranged from 0.405 to $14.285 \mu \mathrm{m}$ [24]. The MODIS satellite takes 1 to 2 days to capture all the scenes in the entire world, acquiring data in 36 spectral bands over a $2330 \mathrm{~km}$ swath.

(a)

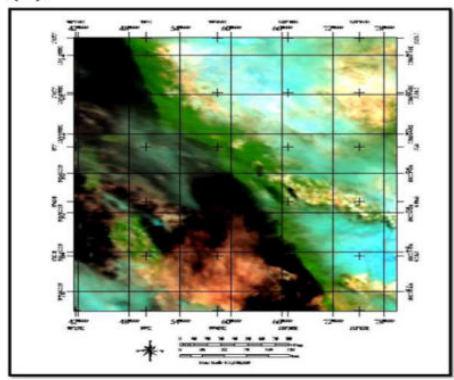

(b)

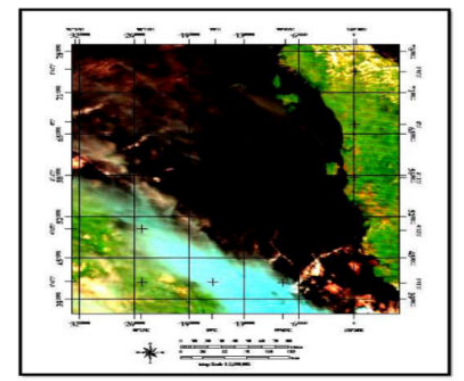

(c)

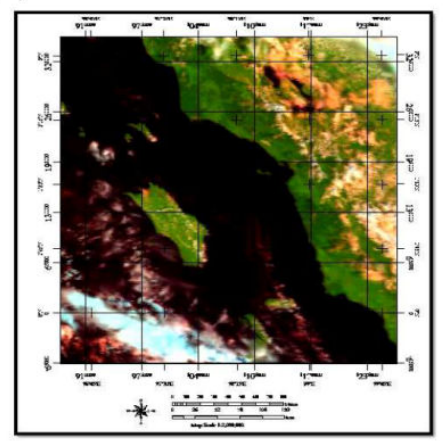

Figure 12. MODIS satellite data (a) pro tsunami event, (b) during Tsunami event and (c) post tsunami event.

It is interesting to find that heavy cloud covers have occurred on December $23^{\text {th }} 2004$ as compared to post tsunami event on December $27^{\text {th }} 2004$ (Figure 12). In fact, Aceh is located on tropical zone where the heavy cloud covers are one of the dominant features. Figure 9 shows the spatial variation of the salinity distribution along Aceh which are derived using the linear least square algorithm. On December 23th 2004, the sea surface salinity ranged between $28 \mathrm{psu}$ to 31 psu. Nevertheless, during the tsunami event $25^{\text {th }} 2004$, the sea surface salinity dramatically 
increased and ranged between $34 \mathrm{psu}$ to $36 \mathrm{psu}$. The sea surface salinity was continued to increase post tsunami event of December $27^{\text {th }} 2004$ and ranged between 37 psu to 38 psu.

The isohaline contours of sea surface salinity which derived from in situ data. These data were acquired from http://aquarius.nasa.gov/. Figure 13 shows that the in situ sea surface salinity were increased dramatically. Pre tsunami event, the isohaline contours were ranged between 28.5 to $29.0 \mathrm{psu}$. However, the isohaline contours were increased to $36.7 \mathrm{psu}$ during tsunami event and continued to increase to 37 psu (Figure 13).

(a)

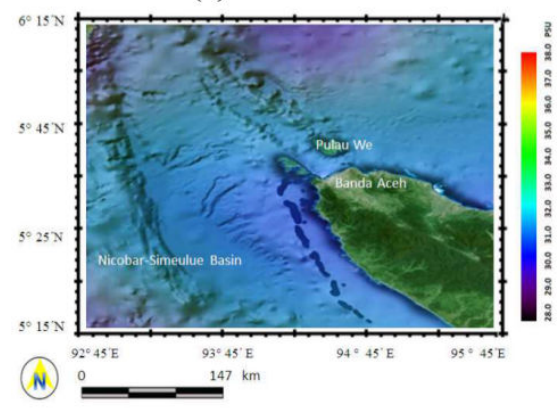

(b)

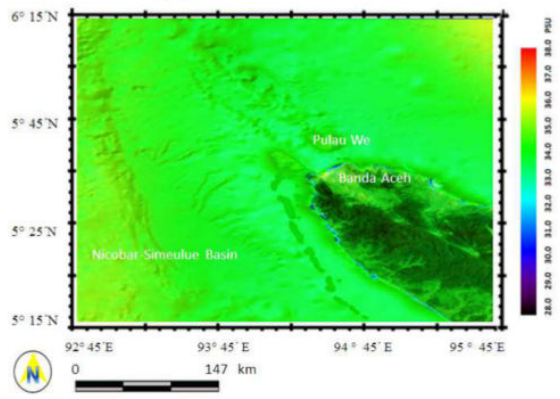

(c)

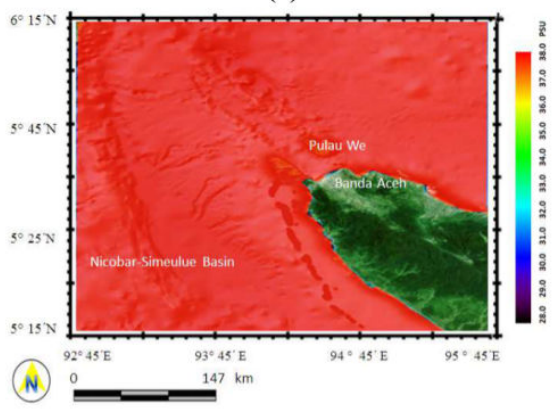

Figure 13. Isohaline contours (a) pro tsunami event, (b) during tsunami event and (c) post tsunami event.

Both MODIS satellite data and in situ data show homogenous sea surface salinity pre tsunami and post tsunami with dramatically increment of sea surface salinity from 28.5 psu to $38.0 \mathrm{psu}$ in coastal waters of Aceh. Figure 15 shows the comparison between in situ sea surface salinity measurements and SSS modeled from MODIS data. Regression model shows that SSS modeled by using linear least square methods are in good agreement with in situ data measurements. The degree of correlation is a function of $\mathrm{r}^{2}$, probability $(\mathrm{p})$ and root mean square of bias (RMSE). The relationship between estimated SSS from MODIS data and in situ data shows positive correlation as $r^{2}$ value is 0.96 with $p<0.00007$ and RMS value of \pm 1.1 psu. Further, accurate results of sea surface salinity in recent study can be explained as: using multiple MODIS bands i.e. 1 to 7 bands is a useful extension of linear regression model is the case where 
SSS is linear function of 7 independent bands. Such a practical is particularly useful when modeling SSS from MODIS data. This statement is agreed with Qing et al., [24].

(a)

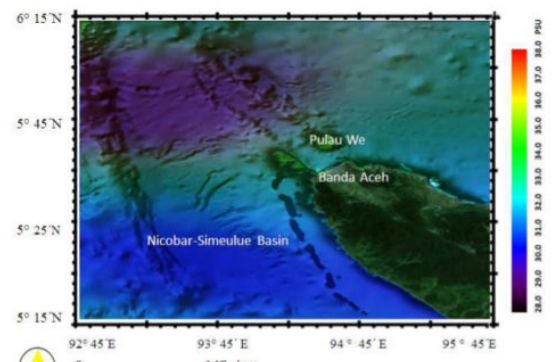

(N) ${ }^{92435 \mathrm{E}} \quad 147 \mathrm{~km}$ (b)

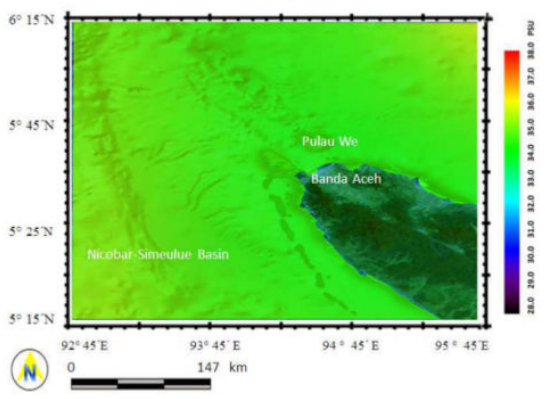

(c)

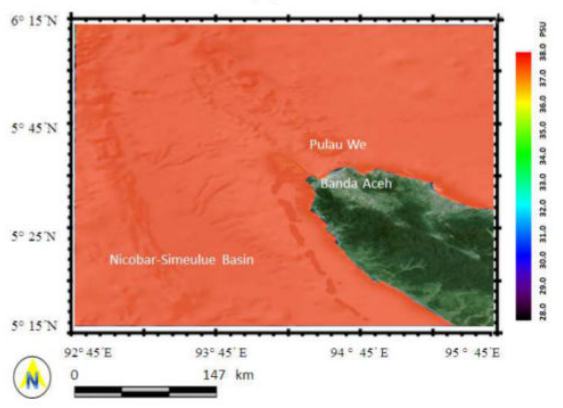

Figure 14. Sea Surface Salinity (SSS) retrieved from MODIS data (a) pro tsunami event, (b) during Tsunami event and (c) post tsunami event.

Further, using least squares method derive a curve that minimizes the discrepancy between estimated SSS from MODIS data and in situ data[16]. This means that using a new approach based on least squares method would be to minimize the sum of the residual errors for the estimating SSS from MODIS data. Further, this study shows the possibilities of direct retrieving of the SSS from visual bands of MODIS satellite data without utilizing such parameter of colored dissolved organic matter, $\mathrm{a}_{\mathrm{CDOM}}$ [15]. This study confirms the studies done by Marghany et al. [18]; Marghany and Mazlan [19].

Further dissolved salts, suspended substances have a major impacts on the electromagnetic radiation attenuation outside the visible spectra range [21]. In this context, the electromagnetic wavelength larger than $700 \mathrm{~nm}$ is increasingly absorbed whereas the wavelength less than 300 $\mathrm{nm}$ is scattered by non-absorbing particles such as zooplankton, suspended sediments and dissolved salts Marghany et al., [17]. 


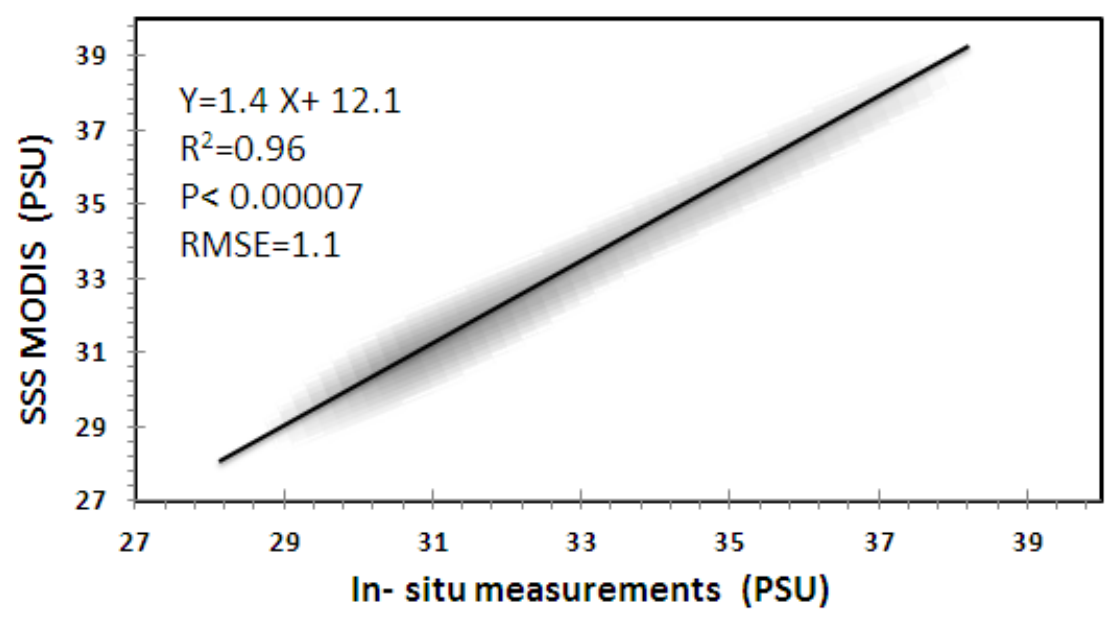

Figure 15. Regression model between in-situ measurement and modeled SSS from MODIS data.

\subsection{Effect of changes the value of salinity towards the ocean}

The Sea Surface Salinity(SSS) along Banda Aceh has been changed dramatically pro and post tsunami event of 2004. During earlier run-up phases, the flows were be extremely strong to erode sediments deposited especially when the coastal topography and bathymetry canalized the tsunami flow. In this regard, the backwash flows were potentially more erosive and powerful than run-up flows because of hyper-concentrated flow routing by coastal morphology. Therefore, tsunami resulted in massive deposits of sand, silt and fine gravel containing isolated boulders [25]. According to Font et al., [22], the area close to the shoreline was eroded by the passing wave front and deposition occurred when the wave front passed by. Just $6 \mathrm{~min}$ later, the direction of the flow close to the shoreline began to change to the seaward direction before the wave front reached the inundation limit. A portion of the sediment entrained by the wave front. In other words, tsunami of 2004 was caused brief coastal flooding with high overland flow velocities and strong abrasion and reworking of the nearshore materials (Figure 16). As most nearshore environments are composed by sand, mud and gravel. In this regard, the salinity values are extremely increased due to tremendous genetic sediment differences carried by wave from inland. According to Moore et al., [23] geochemical proxies have been provided evidence for saltwater inundation, associated coral and/or shell material, highenergy flows (heavy minerals, if present), and possible contamination associated with tsunamis. Finally, Pre and post event imagery can show the extent of erosion and areas most optimal for preservation of tsunami deposits (Figure 17). This information is necessary for comparing different events in the same locality. In addition, In the 2004 tsunami, sediments varied in their salinity levels, so sediments need to be assessed for salinity before any crops are planted in them. 


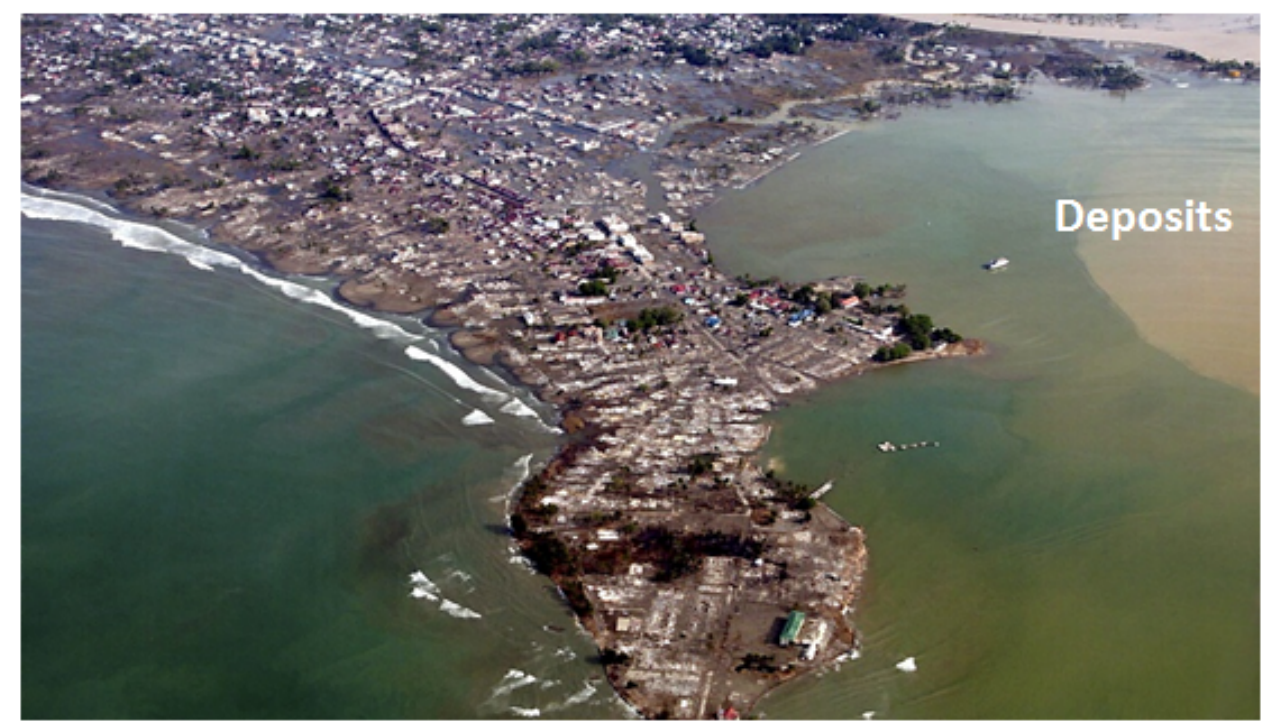

Figure 16. High deposits flow due tsunami 2004 along Aceh coastal waters.

(a)

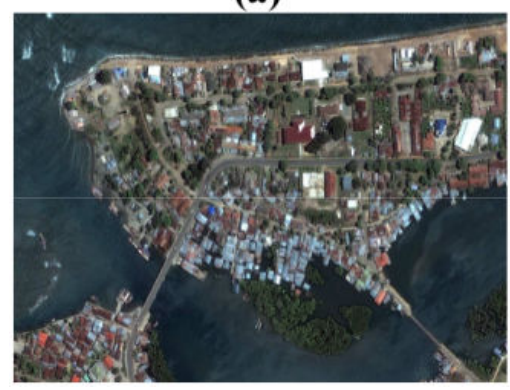

(b)

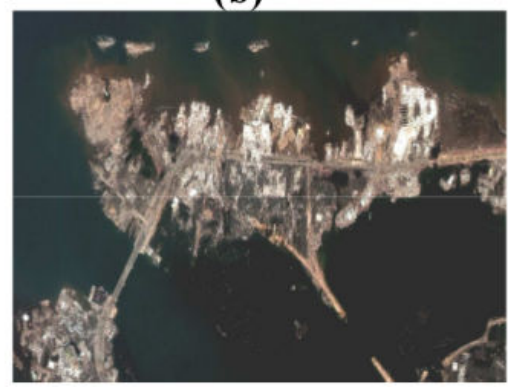

Figure 17. Satellite data along Aceh coastal waters (a) pro and (b) post tsunami event 2004 event.

In general, different grain size of sediments deposited in the coastal waters of Banda Aceh have increased the salinity in the sea surface. Indeed, these sediments contain different level of salts and mineral concentration. Post-tsunami, SSS has increased extremely because the sea coast was rough and turbid with suspended sediments (Figures 16 and 17). This is excellent evident of additional of extremely high amount of salts and minerals due high level of sediment deposit concentration in the coastal waters of Banda Aceh. This study confirms the work done by Saraf et al., [26]. 


\section{Conclusions}

Remote sensing technology has been recognized as powerful tool for environmental disaster studies. Ocean surface salinity is considered as a major element in the marine environment. In this study, we simulated the tsunami 2004 impacts on the Sea Surface Salinity along Banda Aceh using the least square algorithm from MODIS satellite data. This study shows significant variations in the values of SSS pro, during and post the tsunami event. The maximum salinity was observed post tsunami event was 38 psu as compared to before and during tsunami event. The results also show a good correlation between in situ SSS measurements and the SSS that is retrieved from MODIS satellite data with high $\mathrm{r}^{2}$ of 0.96 and RMSE of bias value of \pm 1.1 psu.In conclusion, the least square algorithm is an appropriate method to retrieve SSS from MODIS satellite data. Clearly, the tsunami 2004 has significant impacts on the SSS because of high sediment deposit concentrations which added more salts and minerals to coastal waters of Banda Aceh.

\section{Author details}

Maged Marghany*

Institute of Geospatial and Science Technology (INSTEG), University of Technology, Malaysia

\section{References}

[1] Dawson A, Stewart I, Tsunami Geoscience Progress in Physical Geography. 2007, 31(6) 575- 590.

[2] University of Washington. Earth \& Space science: The Physics of Tsunamis. http:// earthweb.ess.washington.edu/tsunami/general/physics/physics.html(accessed 11 November 2013).

[3] Taru T, Japan Experts Warn of Future Risk of Giant Tsunami. http:// www.cosmostv.org/2012/04/japan-experts-warn-of-future-risk-of.html. (accessed 11 November 2013).

[4] Valdes R, Halabrin N, Lamb R How Tsunamis Work. http://science.howstuffworks.com/nature/natural-disasters/tsunami.htm. (accessed 11 November 2013).

[5] Zahibo N, Pelinovsky E, Talipova T, Kozelkov A, Kurkin A. Analytical and numerical study of nonlinear effects at tsunami modelling. Applied Mathematics and Computation. 2006 (174) 795- 809. 
[6] Zaitsev A, Kurkin A, Levin B, Pelinovsky E, Yalciner A C, Troitskaya Y, Ermakov S. Modeling of propagation of the catastrophic tsunami (December 26, 2004) in the Indian Ocean, Doklady Earth Sci. 403 (3) (2005).

[7] V V and Synolakis C E. Numerical modeling of 3-D long wave runup using VTCS-3. In Long Wave Runup Models, P. Liu, H. Yeh, and C. Synolakis (eds.), World Scientific Publishing Co. Pte. Ltd., Singapore, 1996 242-248.

[8] Haugen K B, Løvholt F, Harbitz C B. Fundamental mechanisms for tsunami generation by submarine mass flows in idealised geometries. Marine and Petroleum Geology. 2005 (22) 209- 217.

[9] Liu P L F, Wu T R, Raichlen F, Synolakis C. and Borrero J. Runup and rundown generated by three-dimensional sliding masses. Journal Fluid Mech. (2005) (536),107144 .

[10] Kelmelis JA, Schwartz L, Christian C, Crawford M, and King D. Use of Geographic Information in Response to the Sumatra-Andaman Earthquake and Indian Ocean Tsunami of December 26, 2004. Phototogrammetric Engineering \& Remote Sensing. $200672(8)$ 862-876.

[11] Abbott P L. Natural Disasters. $6^{\text {th }}$ edition, 2008, McGraw Hill Higher Education, New York.

[12] Catherine J K, Gahalaut V K, Ambikapathy A, Kundu B, C. Subrahmanyam, S. Jade, Amit Bansal, R.K. Chadha, M. Narsaiah, L. Premkishore, D.C. Gupta. 2008 Little Andaman aftershock: Genetic linkages with the subducting $90^{\circ} \mathrm{E}$ ridge and 2004 Sumatra-Andaman earthquake. Tectono physics 2009 (479) 271-276.

[13] Shulgin A, Kopp H, Klaeschen D, Papenberg C, Tilmann F, Flueh E R, Franke D, Barckhausen U, Krabbenhoeft A, Djajadihardja Y. Subduction system variability across the segment boundary of the 2004/2005 Sumatra megathrust earthquakes. Earth and Planetary Science Letters 365 (2013) 108-119.

[14] Titov V V, Gonzalez F I, Bernard E N, et al. (2005): In: Real-time tsunami forecasting: challenges and solutions. Nat. Hazards 35(1), Special Issue, pp. 41-58. US National Tsunami Hazard Mitigation Program.

[15] Ahn Y H, Shanmugam P, Moon J E, and Ryu J H. Satellite remote sensing of a lowsalinity water plume in the East China Sea. Annals of Geophys. 2008 (26) 2019-2035.

[16] Marghany M. Linear algorithm for salinity distribution modelling from MODIS data, Geoscience and Remote Sensing Symposium,2009 IEEE International, IGARSS 2009, 12-17 July 2009, Cape Town, South Africa, 2009 (3) III-365-III-368.

[17] Marghany M. Examining the Least Square Method to Retrieve Sea Surface Salinity from MODIS Satellite Data European Journal of Science of Research. 40 (2010) 377-386. 
[18] Marghany M Hashim M and Cracknell A P. Modelling Sea Surface Salinity from MODIS Satellite Data. Computational Science and Its Applications - ICCSA 2010, Lecture Notes in Computer Science. 2010, (6016) 545-556.

[19] Marghany M and Hashim M. A numerical method for retrieving sea surface salinity from MODIS satellite data. International Journal of the Physical Sciences. 2011 6(13) 3116-3125.

[20] Hu C, Chen T, Clayton P, Swarnzenski J, Brock I, and Muller-Karger F. Assessment of estuarine water-quality indicators using MODIS medium-resolution bands: Initial results from Tampa Bay, fL. Remote Sensing of Environment 2004 (93) 423-441

[21] Wong M S, Kwan L, Young J K, Nichol J, Zhangging L, Emerson N Modelling of suspendid solids and sea surface salinity in Hong Kong using Aqua/ MODIS satellite images. Korian Journal of Remote sensing. 2007 (23) 161-169.

[22] Font E, Nascimento C, Omira R, Baptista MA, Silva PA.Identification of tsunami-induced deposits using numerical modelling and rock magnetism techniques: A study case of the 1755 Lisbon tsunami in Algarve, Portugal. Physics of the Earth and Planetary Interiors. 2010 (182) 187-198.

[23] Moore A, Nishimura Y, Gelfenbaum G, Kamataki T, and Triyono R, Sedimentary deposits of the 26 December 2004 tsunami on the northwest coast of Aceh, Indonesia. Earth Planets Space, 2006 (58) 253-258.

[24] Qing S Zhang J Cui T Bao Y. Retrieval of sea surface salinity with MERIS and MODIS data in the Bohai Sea. Remote Sensing of Environment. 2013 (136) 117-125.

[25] Anthony E J. Developments in marine geology: Shore Processes and their palaeoenvironmental applications. Series Editor Chamley H, 2009 (4) 415-420.

[26] Saraf A K, Choundhury and Dasgupta S. Satellite observation of the great mega thrust Sumatra earthquake activities. International journal of Geoinformatics. 2005, 1(4) 67-74. 
